Supporting Information

\title{
Plasmonically Engineered Textile Polymer Solar Cells for High-Performance, Wearable Photovoltaics
}

Seok Ho Cho, ${ }^{1}$ Jaegab Lee, ${ }^{2}$ Mi Jung Lee, ${ }^{2}$ Hyo Jin Kim, ${ }^{3}$ Sung-Min Lee, ${ }^{2 *}$ and Kyung Cheol Choi ${ }^{4 *}$

${ }^{1}$ Department of Clothing and Textiles, Chonnam National University, 77, Yongbong-ro, Buk-gu, Gwangju 61186, Republic of Korea

${ }^{2}$ School of Materials Science and Engineering, Kookmin University, 77 Jeongneung-ro, Seongbukgu, Seoul 02707, Republic of Korea

${ }^{3}$ Photonic Energy Research Center, Korea Photonics Technology Institute, 108 Chumdanbencheo-ro, Buk-gu, Gwangju 61007, Republic of Korea

${ }^{4}$ School of Electrical Engineering, KAIST, 291 Daehak-ro, Yuseong-gu, Daejeon 34141, Republic of Korea

Corresponding authors:

Sung-Min Lee (sungminlee@kookmin.ac.kr), Kyung Cheol Choi (kyungcc@kaist.ac.kr) 


\section{Supporting Figures and Captions}

(a)

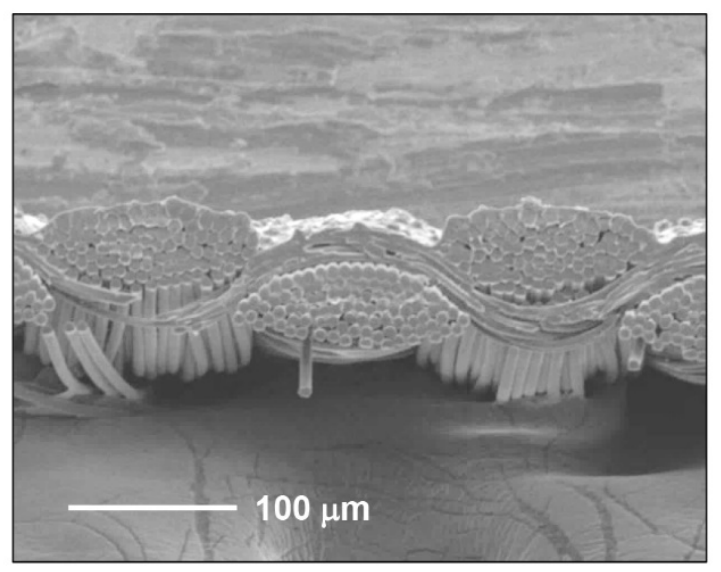

(c)

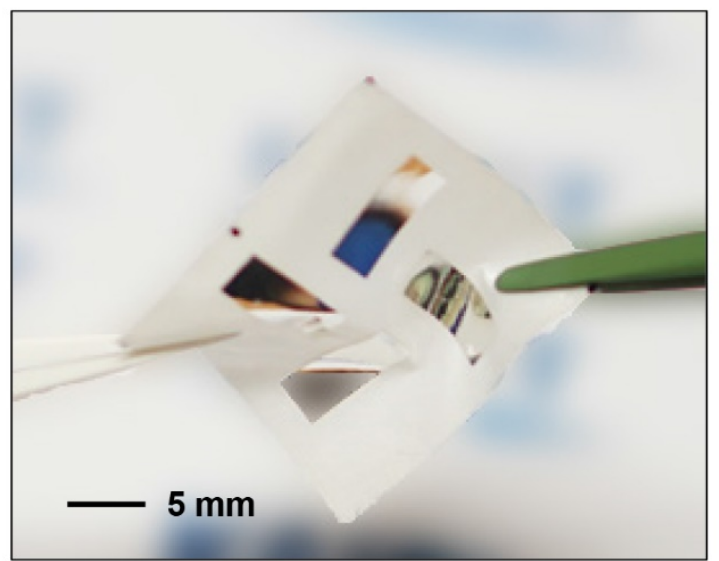

(b)

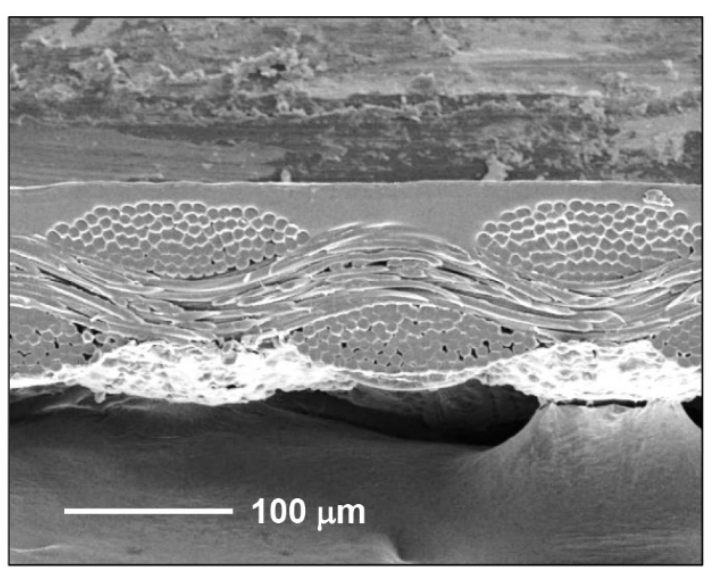

(d)

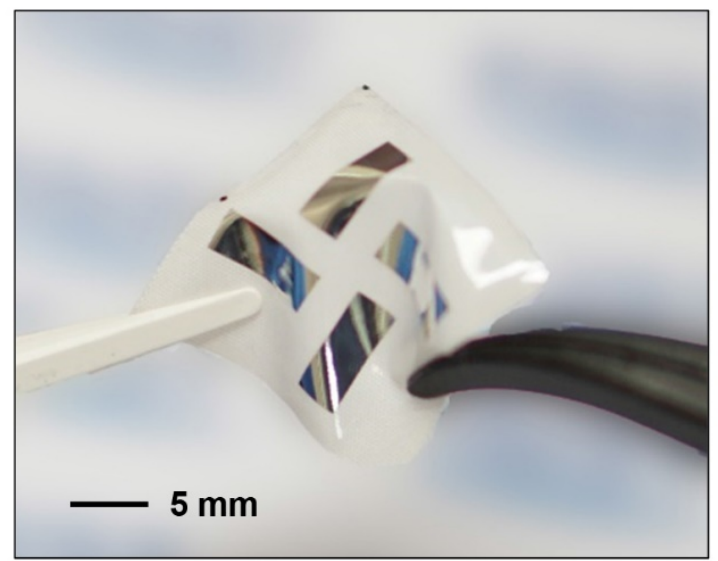

Figure S1. (a,b) Cross-sectional SEM images of (a) unprocessed (i.e. bare) and (b) planarizationprocessed woven fabrics. (c,d) Photographic images of the planarization-processed woven fabrics with the nanostructured Ag cathode that are crumpled to show their conformability. 
(a)

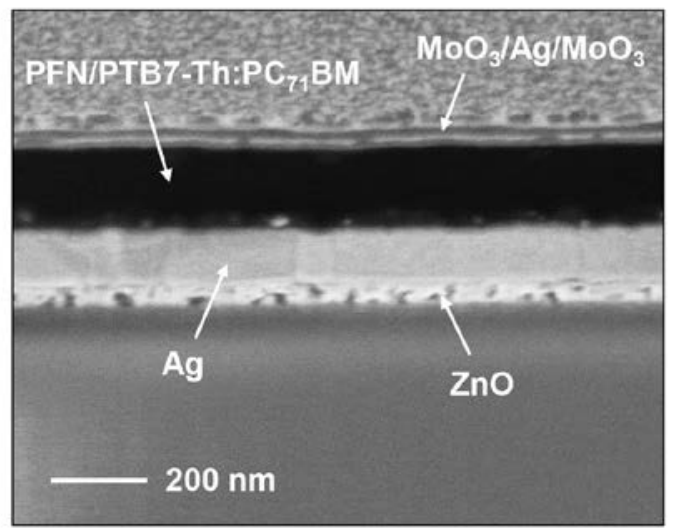

(b)

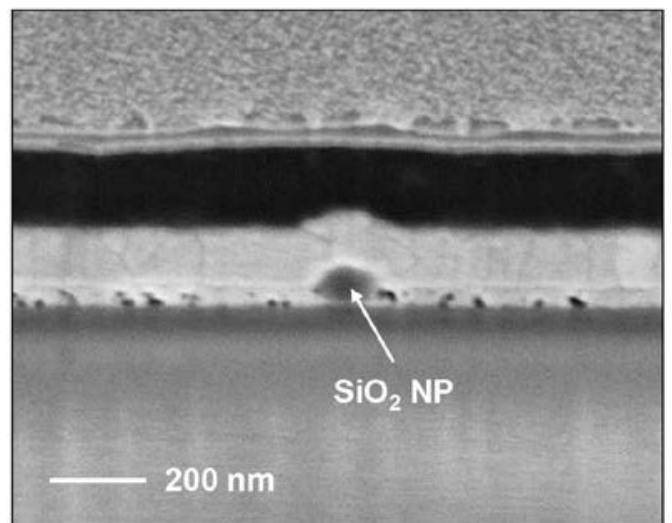

Figure S2. Cross-sectional SEM images of (a) planar PSC and (b) plasmonic PSC formed with the 5 vol\% blended nanoparticle solution. 
(a)

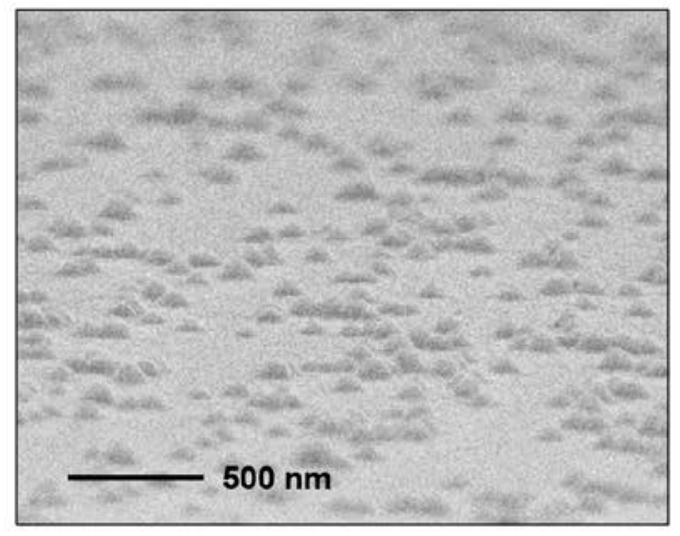

(c)

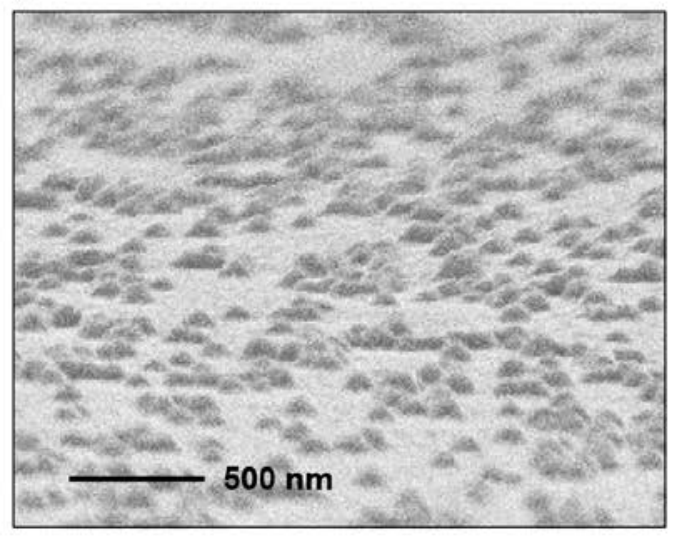

(e)

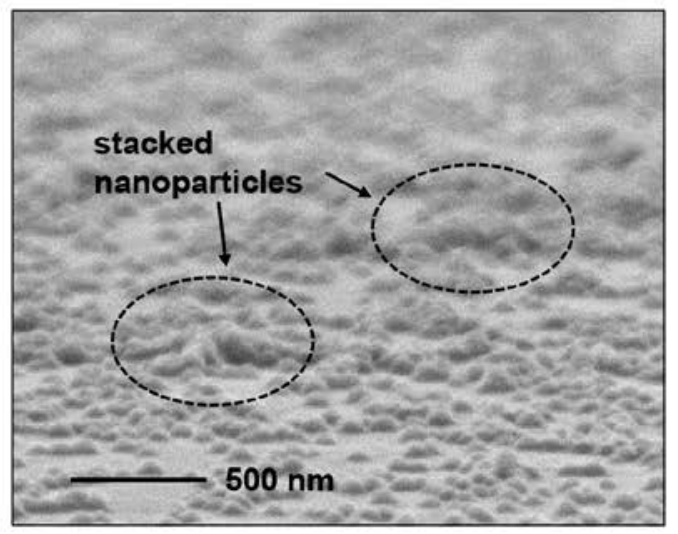

(b)

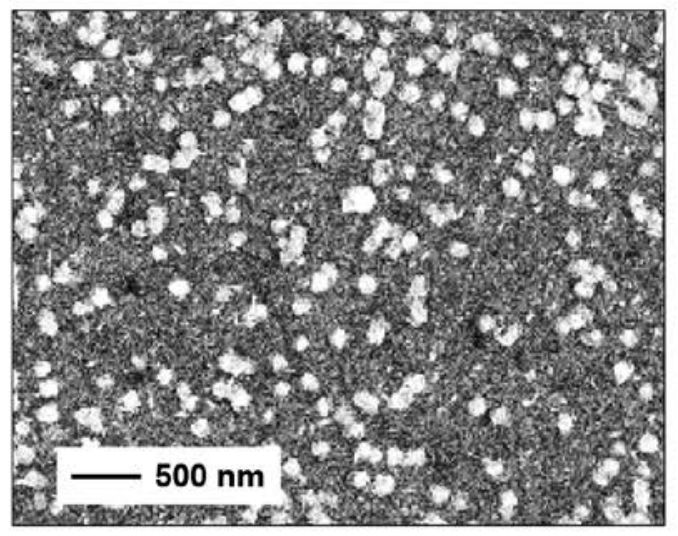

(d)

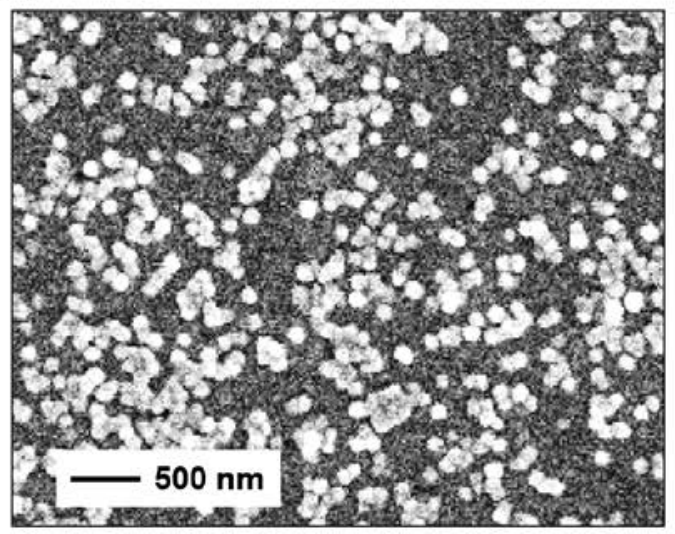

(f)

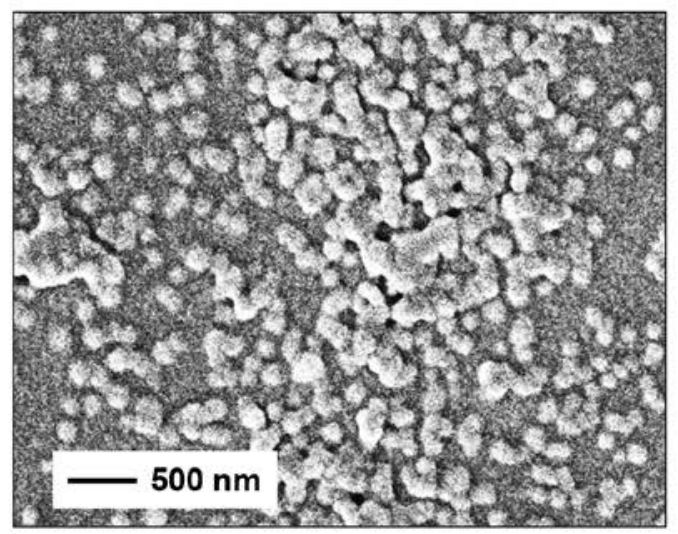

Figure S3. Tilted-view (left) and top-view (right) SEM images of disorderly distributed Ag elliptical hemispheres formed with the blended nanoparticle solutions of (a,b) 5, (c,d) 10, and (e,f) 15 vol\%, respectively.. 


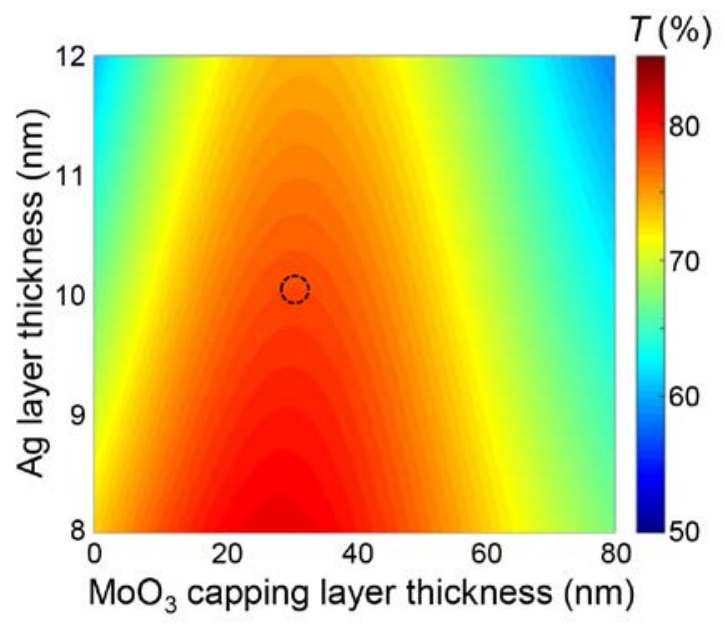

Figure S4. Contour plot of calculated transmission averaged over the wavelength range of 350 $800 \mathrm{~nm}$ for $\mathrm{MoO}_{3} / \mathrm{Ag} / \mathrm{MoO}_{3}$ electrodes as a function of thicknesses of $\mathrm{Ag}$ and $\mathrm{MoO}_{3}$ capping layers at a fixed thickness of $\mathrm{MoO}_{3}$ bottom layer of $10 \mathrm{~nm}$. 


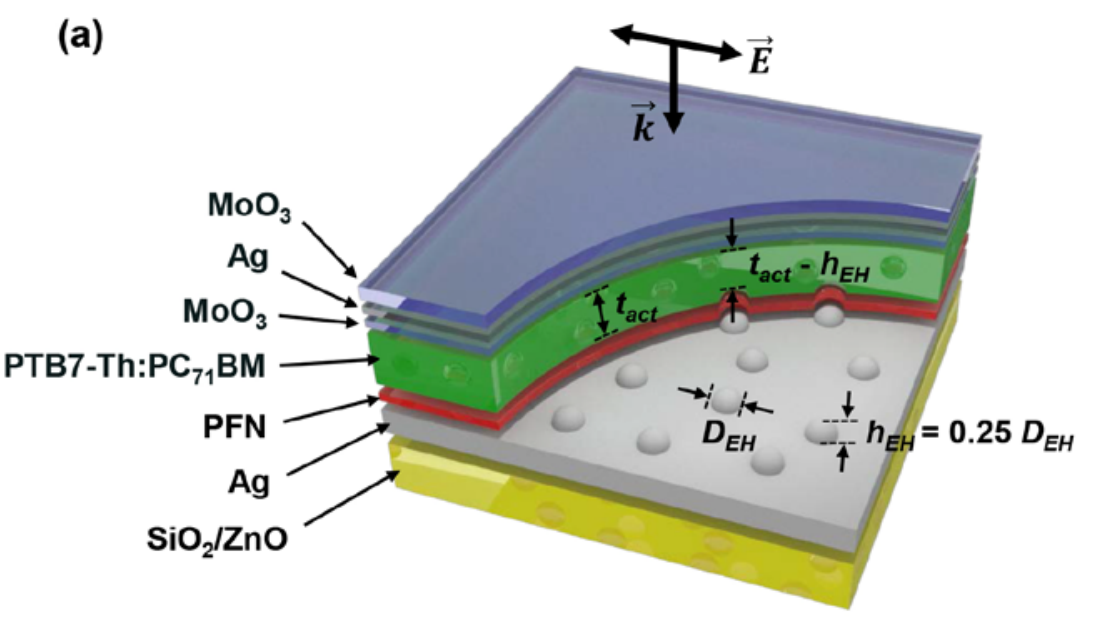

(b)

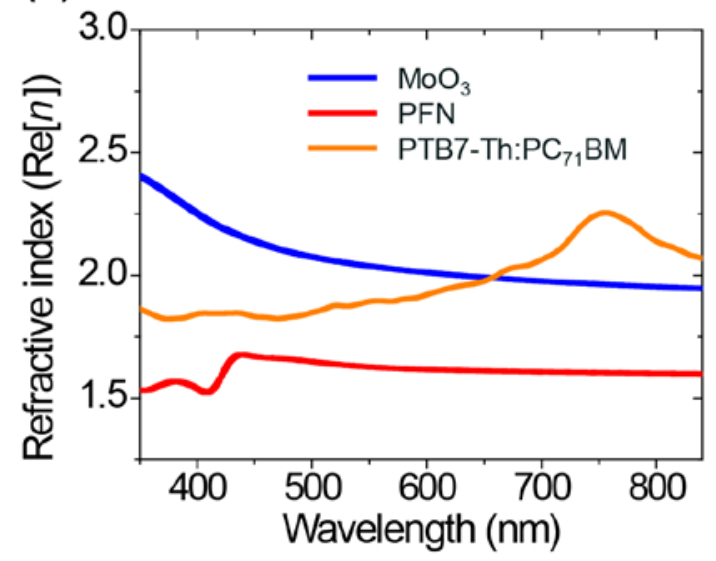

(c)

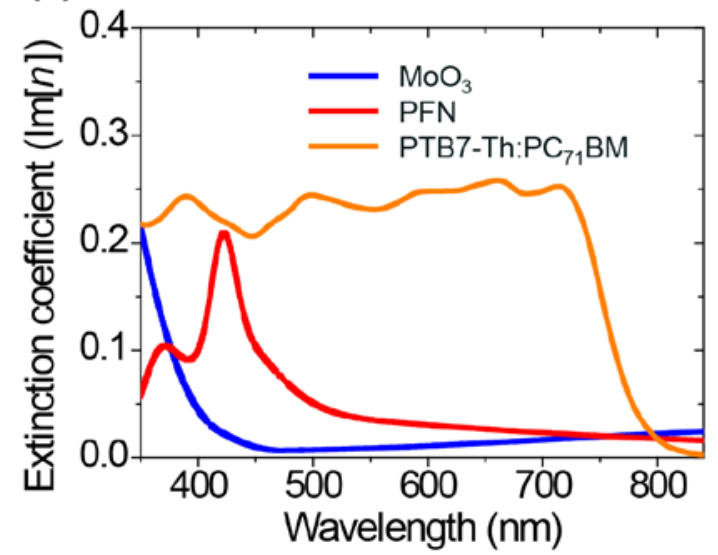

Figure S5. (a) Schematic illustration of the plasmonic PSC structure designed for the FDTD simulation. (b,c) Measured (b) refractive index $(\operatorname{Re}[n])$ and (c) extinction coefficient $(\operatorname{Im}[n])$ spectra of constituent materials used in the simulation. 
(a)

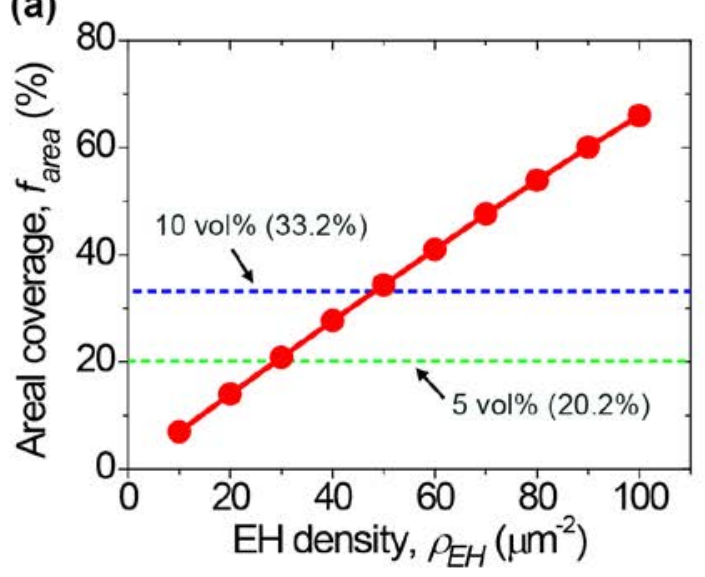

(c)

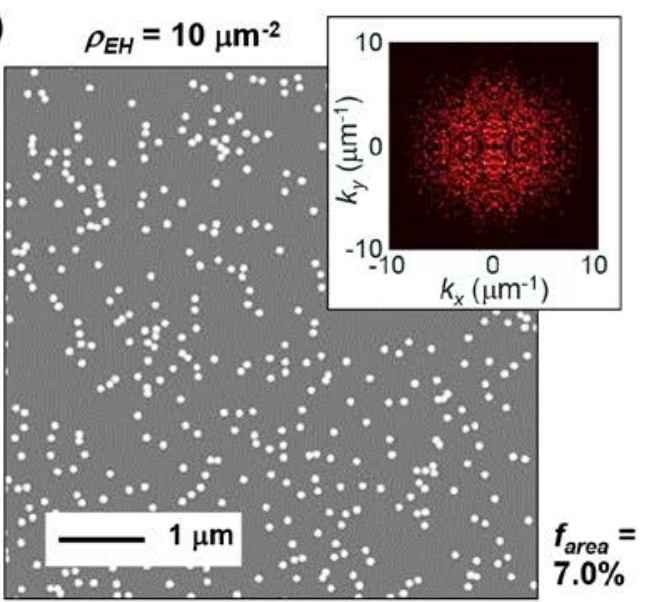

(e)

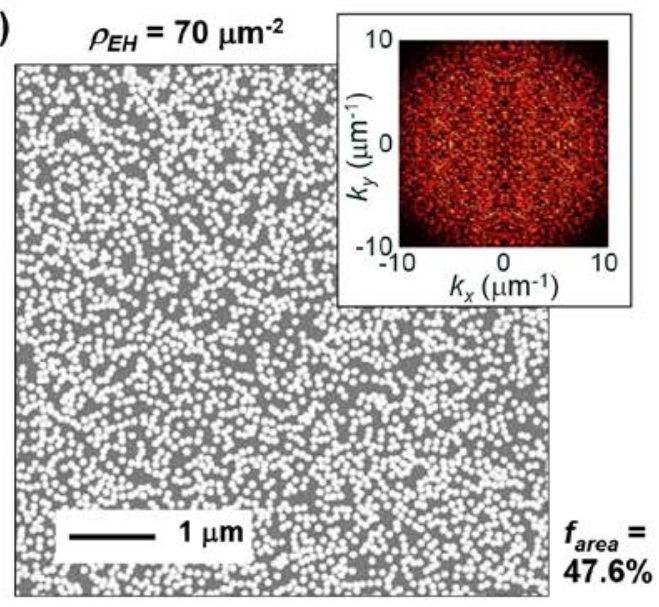

(b) 5 vol\% (exp)

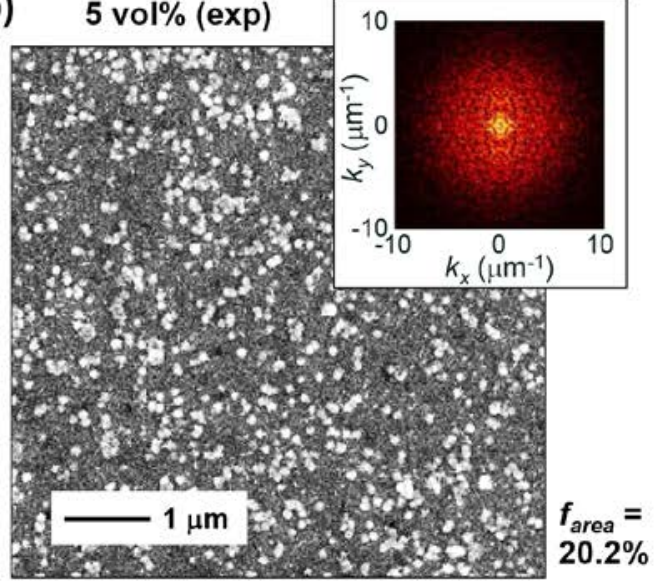

(d)

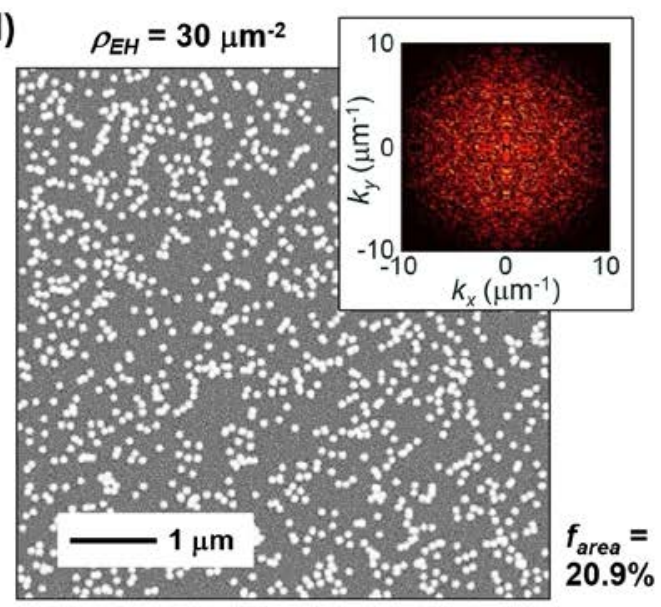

(f)

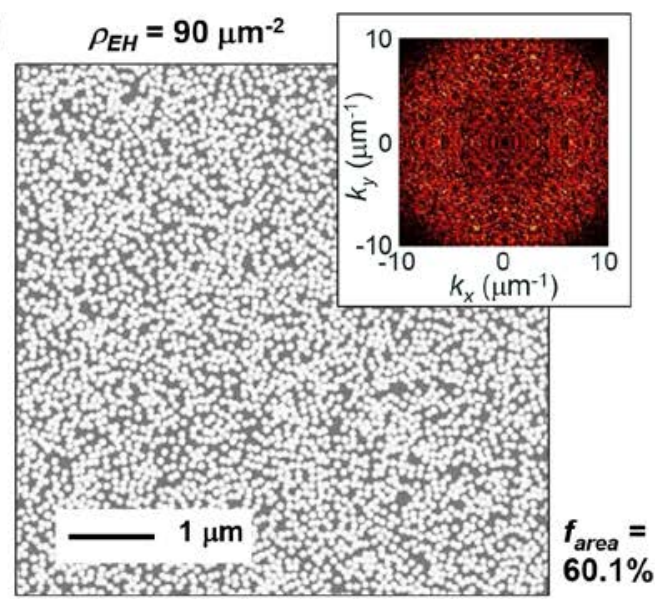

Figure S6. (a) Calculated areal coverage fraction ( $\left.f_{\text {area }}\right)$ of the modeled distribution of elliptical hemispheres (EHs) as a function of the EH density $\left(\rho_{E H}\right)$ at a fixed $D_{E H}$ of $100 \mathrm{~nm}$. The $f_{\text {area }}$ values of experimental samples formed with 5 and $10 \%$ vol\% blended solutions $\left(D_{N P}=70 \mathrm{~nm}\right)$ are also presented for comparison. (b) Top-view SEM image of the experimental EH distribution (5 vol\%, $D_{N P}=70 \mathrm{~nm}$ ). (c-f) Illustrated images of the modeled EH distributions with $\rho_{E H S}$ of (c) 10, (d) 30, (e) 70, and (f) $90 \mu \mathrm{m}^{-2}$ a fixed $D_{E H}$ of $100 \mathrm{~nm}$. The insets of (b) (f) show FFT spectra of the corresponding distributions, respectively. 
(a)

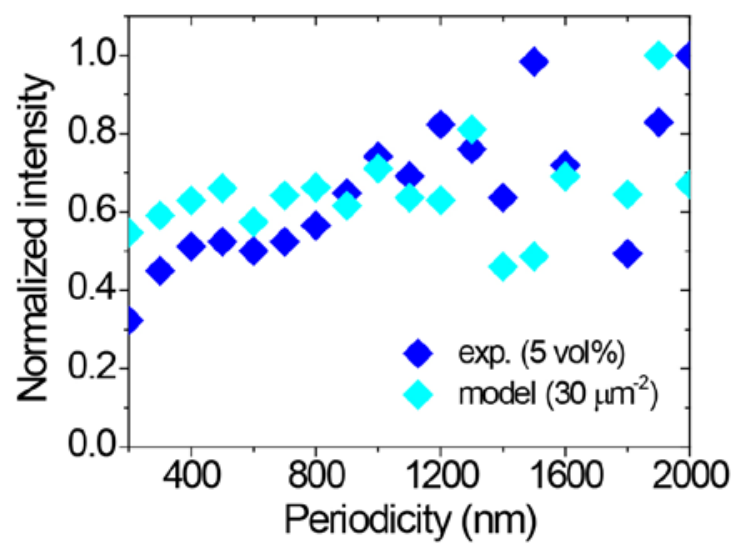

(b)

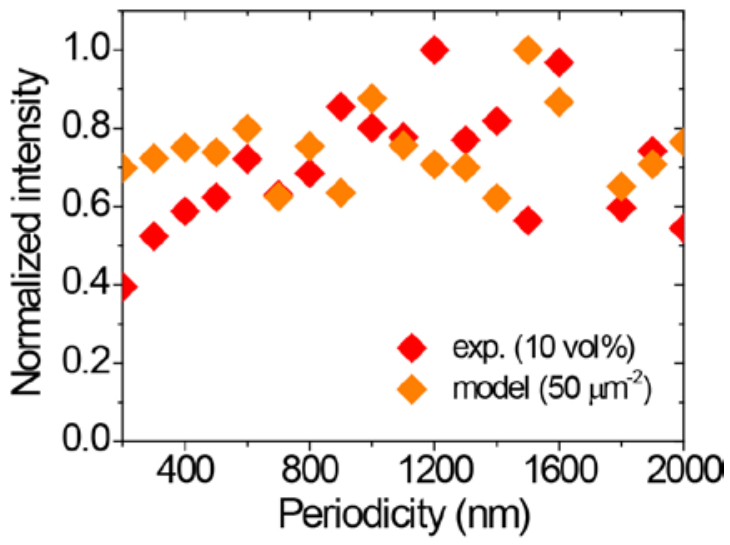

Figure S7. One-dimensional power spectra obtained from the two-dimensional FFT of experimental and modeled distributions of elliptical hemispheres for cases of (a) 5 vol\% (experiment) and $30 \mu \mathrm{m}^{-2}$ (modeling) and (b) $10 \mathrm{vol} \%$ (experiment) and $50 \mu \mathrm{m}^{-2}$ (modeling). 
(a)

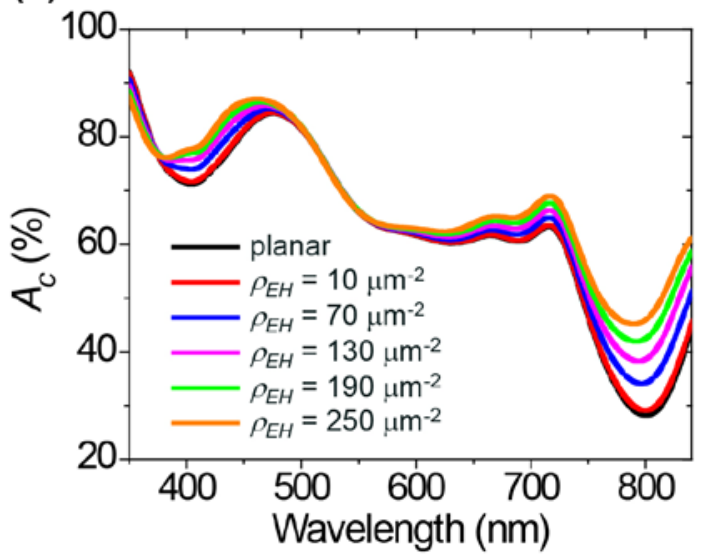

(c)

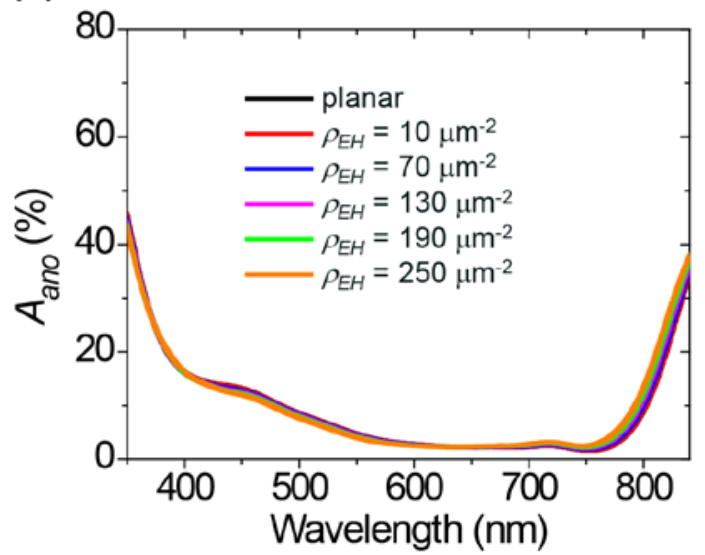

(e)

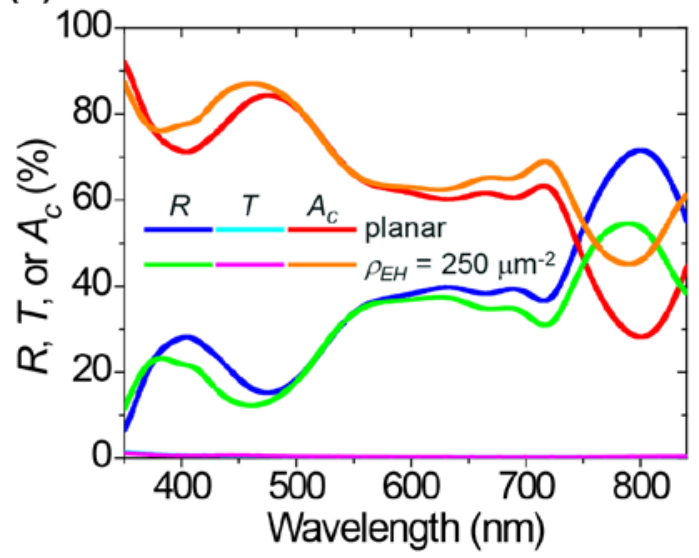

(b)

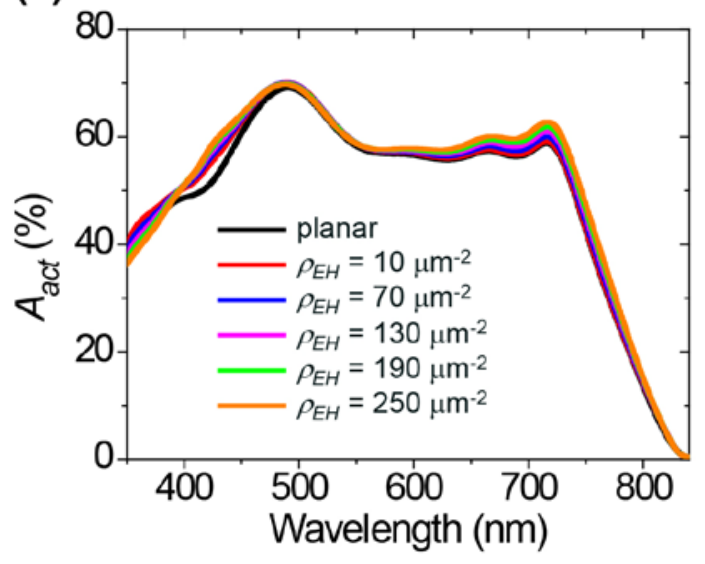

(d)

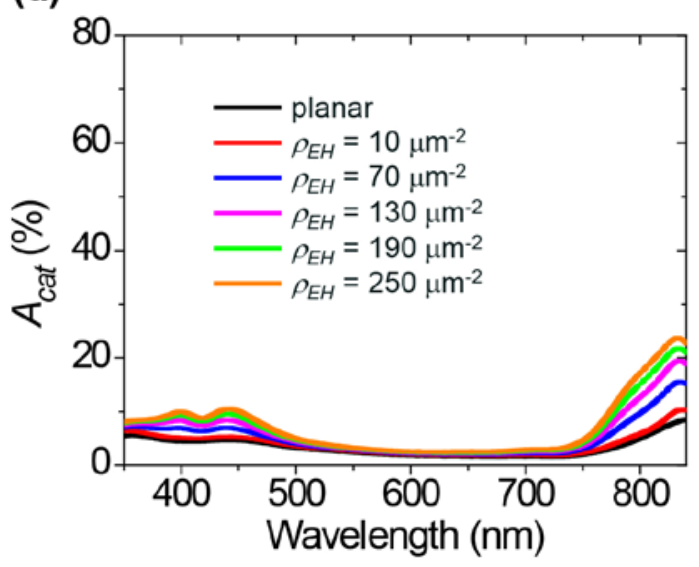

(f)

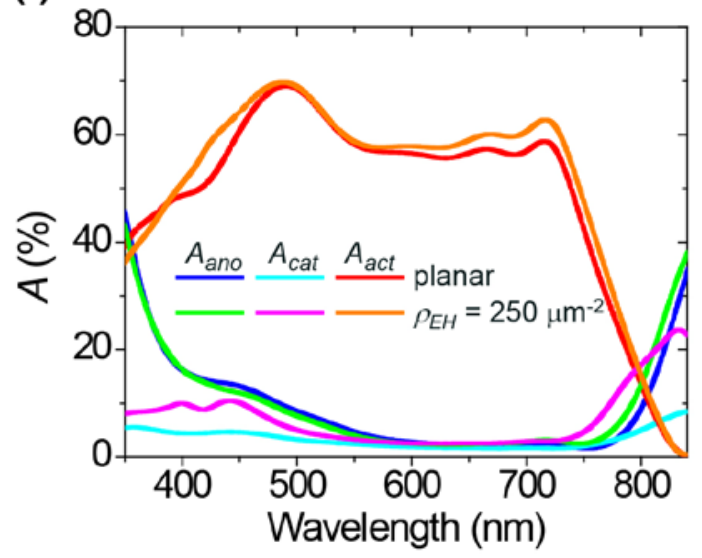

Figure S8. (a-d) Calculated absorption spectra of (a) entire cell $\left(A_{c}\right)$, (b) active layer $\left(A_{a c t}\right)$, (c) anode $\left(A_{a n o}\right)$, and $(\mathrm{d})$ cathode $\left(A_{c a t}\right)$ for the planar cell and the plasmonic cells with various $\rho_{E H S}$ of $10 \sim 250 \mu \mathrm{m}^{-2}$ at a fixed $D_{E H}$ of $60 \mathrm{~nm}$. (e) Calculated reflection $(R)$, transmission $(T)$, and entire absorption $\left(A_{c}\right)$ spectra of the planar cell and the optimal $\left(\rho_{E H}=250 \mu \mathrm{m}^{-2}\right)$ plasmonic cell at $D_{E H}=$ $60 \mathrm{~nm}$. (f) $A_{a n o}, A_{c a t}$, and $A_{a c t}$ spectra of the planar and plasmonic cells of (e). 
(a)

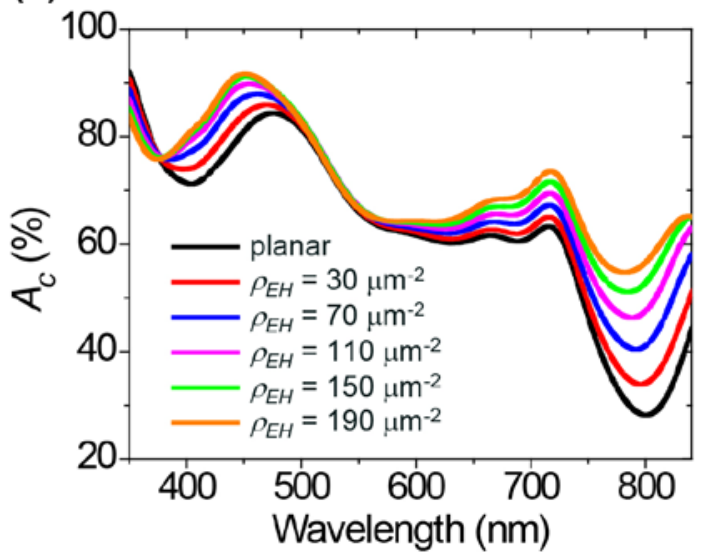

(c)

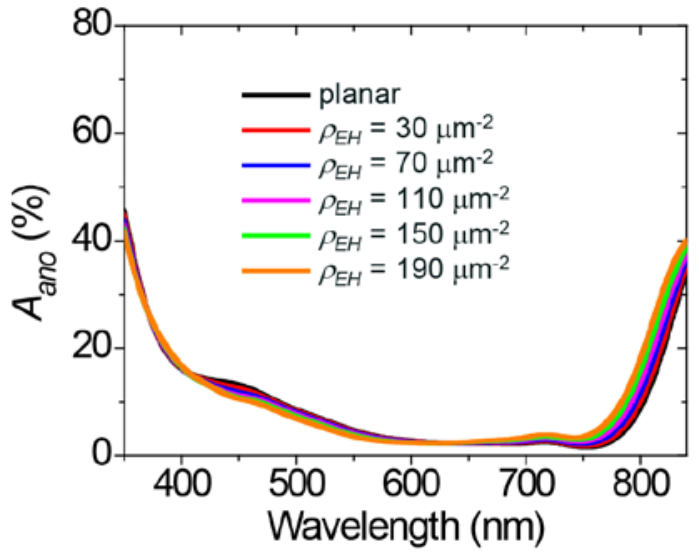

(e)

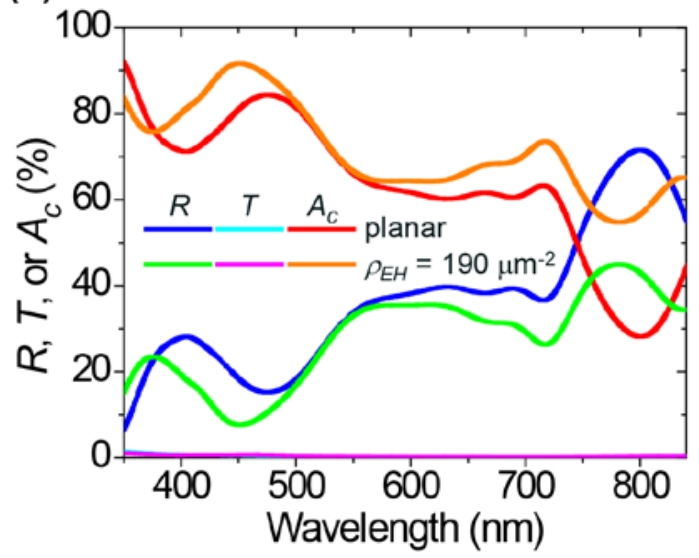

(b)

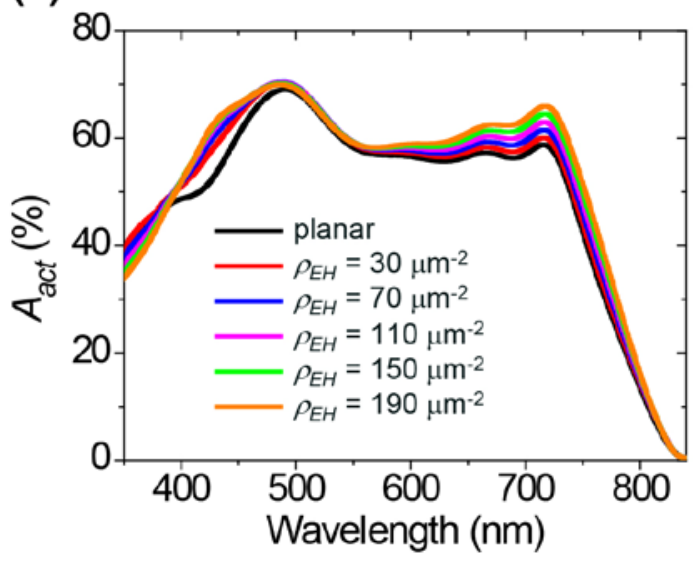

(d)

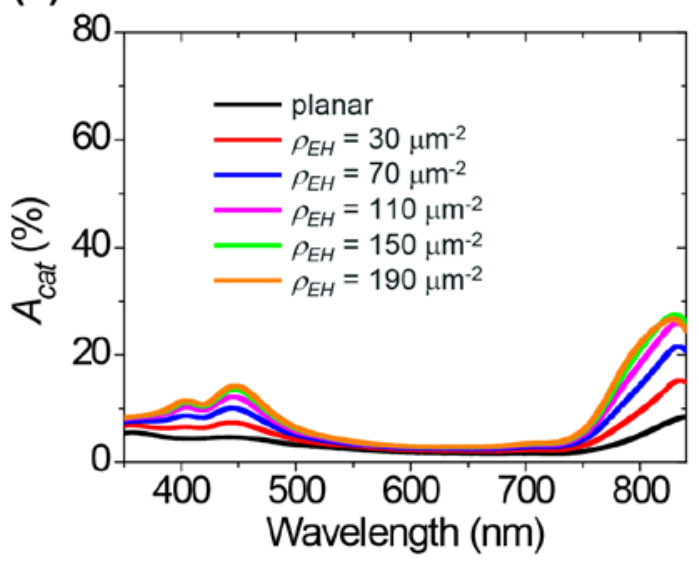

(f)

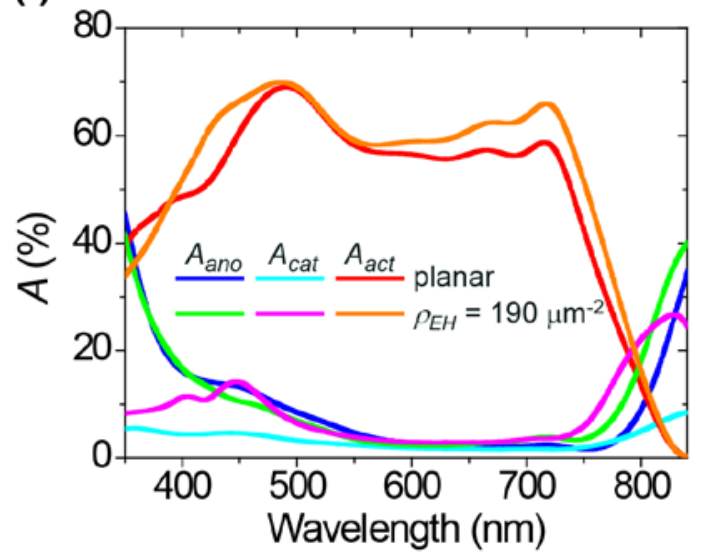

Figure S9. (a-d) Calculated absorption spectra of (a) entire cell $\left(A_{c}\right)$, (b) active layer $\left(A_{a c t}\right)$, (c) anode $\left(A_{\text {ano }}\right)$, and (d) cathode $\left(A_{c a t}\right)$ for the planar cell and the plasmonic cells with various $\rho_{E H S}$ of $30 \sim 190 \mu \mathrm{m}^{-2}$ at a fixed $D_{E H}$ of $80 \mathrm{~nm}$. (e) Calculated reflection $(R)$, transmission $(T)$, and entire absorption $\left(A_{c}\right)$ spectra of the planar cell and the optimal $\left(\rho_{E H}=190 \mu \mathrm{m}^{-2}\right)$ plasmonic cell at $D_{E H}=$ $80 \mathrm{~nm}$. (f) $A_{\text {ano }}, A_{\text {cat }}$, and $A_{\text {act }}$ spectra of the planar and plasmonic cells of (e). 
(a)

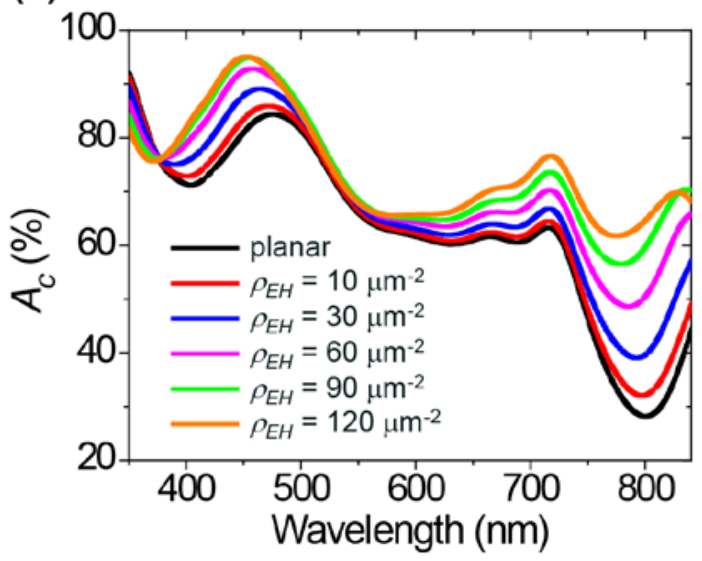

(c)

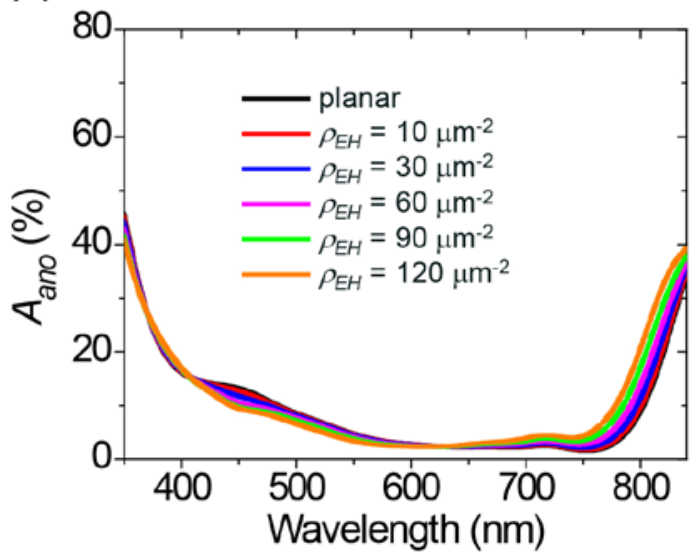

(e)

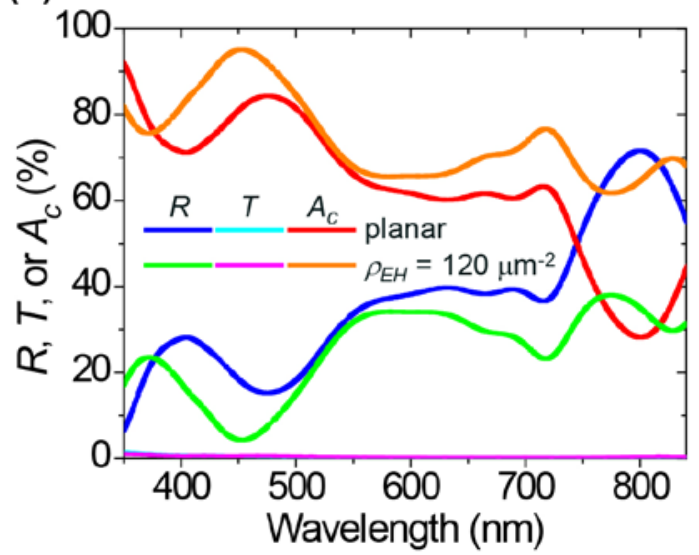

(b)

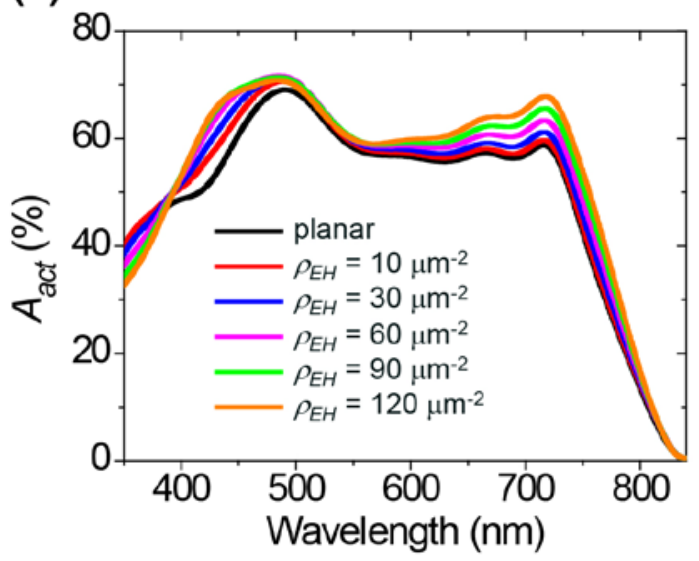

(d)

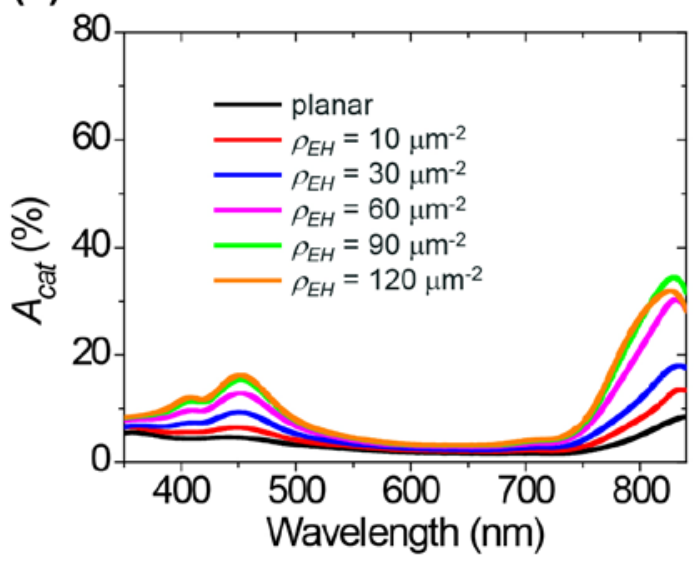

(f)

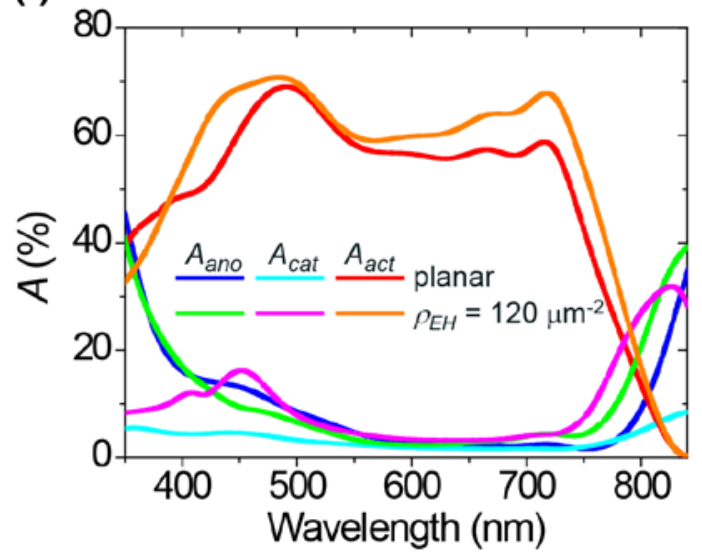

Figure S10. (a-d) Calculated absorption spectra of (a) entire cell ( $\left.A_{c}\right)$, (b) active layer ( $\left.A_{a c t}\right)$, (c) anode $\left(A_{a n o}\right)$, and $(\mathrm{d})$ cathode $\left(A_{c a t}\right)$ for the planar cell and the plasmonic cells with various $\rho_{E H S}$ of $10 \sim 120 \mu \mathrm{m}^{-2}$ at a fixed $D_{E H}$ of $100 \mathrm{~nm}$. (e) Calculated reflection $(R)$, transmission $(T)$, and entire absorption $\left(A_{c}\right)$ spectra of the planar cell and the optimal $\left(\rho_{E H}=120 \mu \mathrm{m}^{-2}\right)$ plasmonic cell at $D_{E H}=$ $100 \mathrm{~nm}$. (f) $A_{a n o}, A_{c a t}$, and $A_{a c t}$ spectra of the planar and plasmonic cells of (e). 
(a)

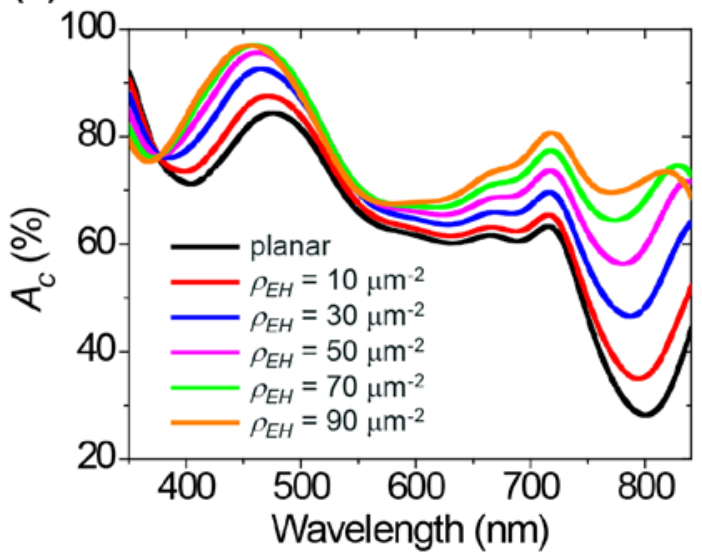

(c)

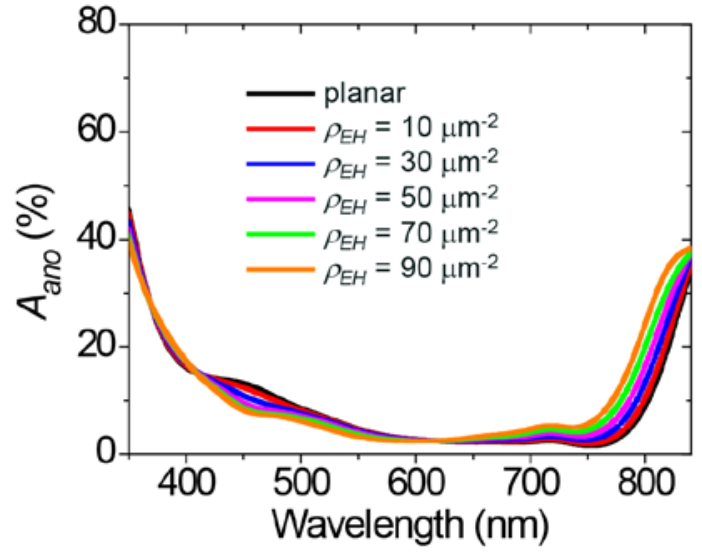

(e)

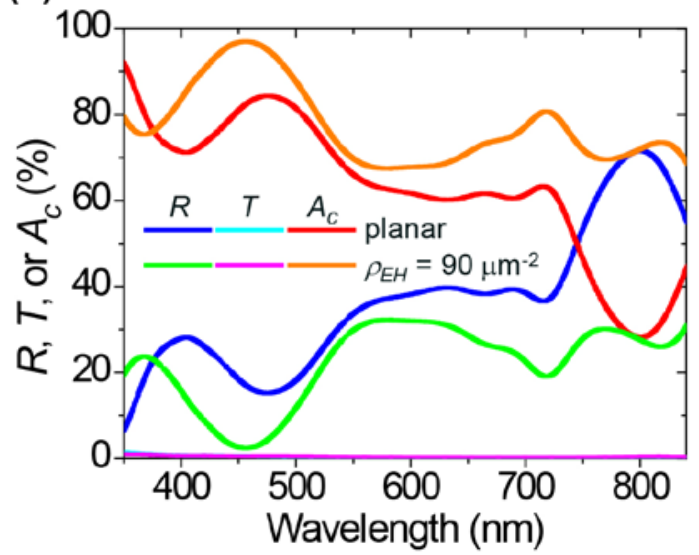

(b)

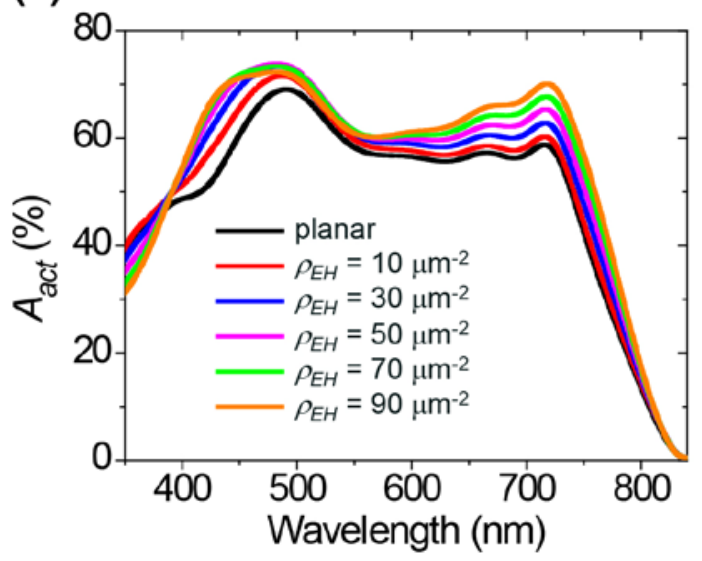

(d)

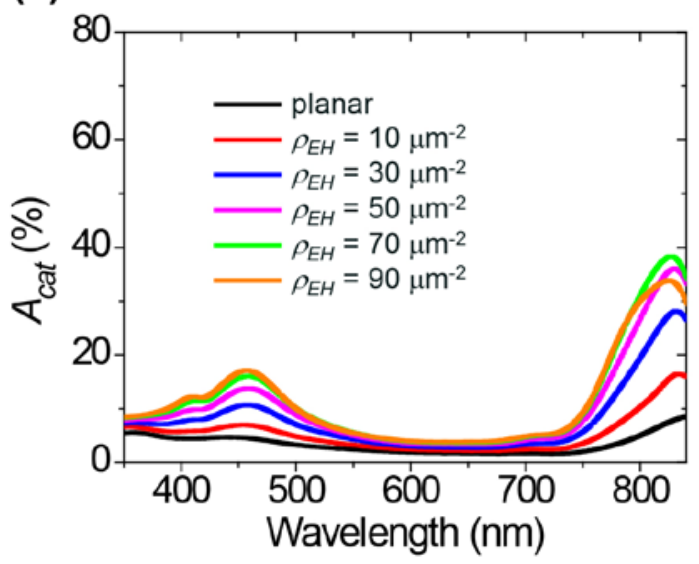

(f)

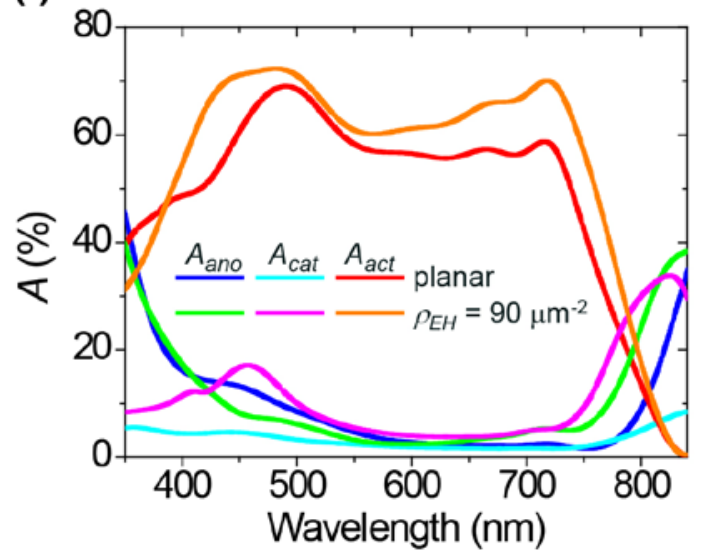

Figure S11. (a-d) Calculated absorption spectra of (a) entire cell ( $\left.A_{c}\right)$, (b) active layer $\left(A_{a c t}\right)$, (c) anode $\left(A_{\text {ano }}\right)$, and (d) cathode $\left(A_{c a t}\right)$ for the planar cell and the plasmonic cells with various $\rho_{E H S}$ of $10 \sim 90 \mu \mathrm{m}^{-2}$ at a fixed $D_{E H}$ of $120 \mathrm{~nm}$. (e) Calculated reflection $(R)$, transmission $(T)$, and entire absorption $\left(A_{c}\right)$ spectra of the planar cell and the optimal $\left(\rho_{E H}=90 \mu \mathrm{m}^{-2}\right)$ plasmonic cell at $D_{E H}=$ $120 \mathrm{~nm}$. (f) $A_{a n o}, A_{c a t}$, and $A_{a c t}$ spectra of the planar and plasmonic cells of (e). 
(a)

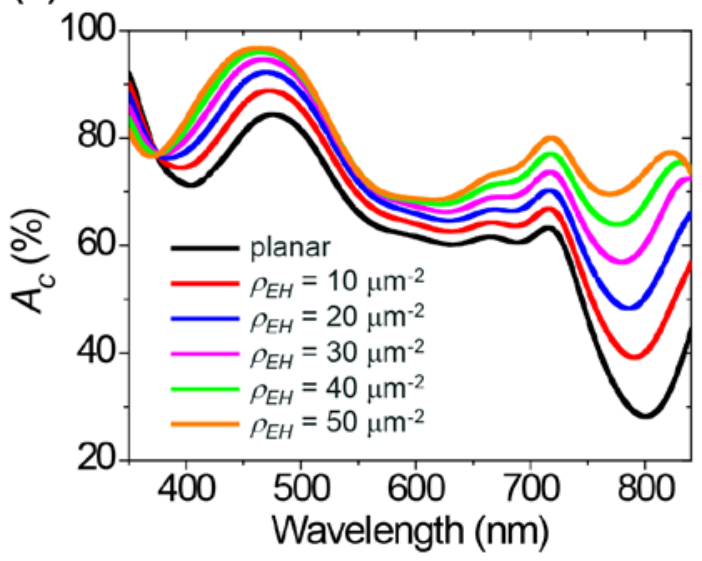

(c)

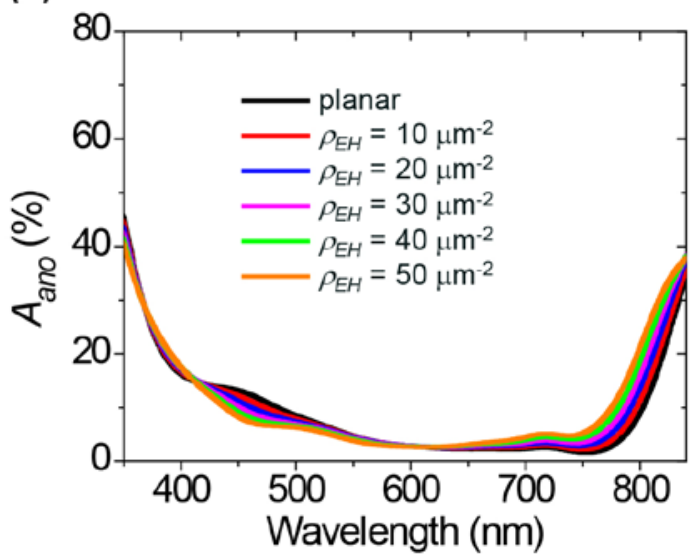

(e)

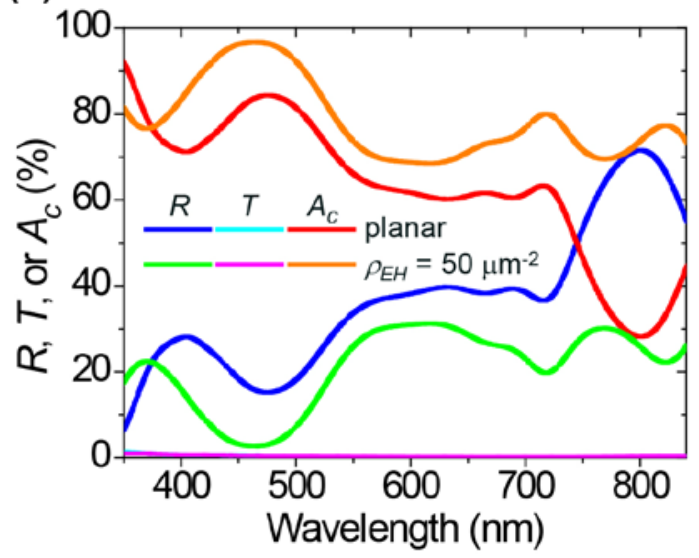

(b)

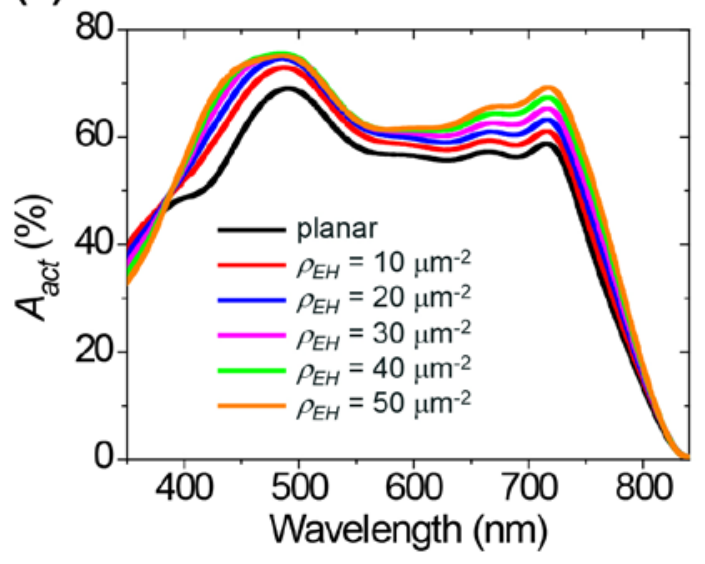

(d)

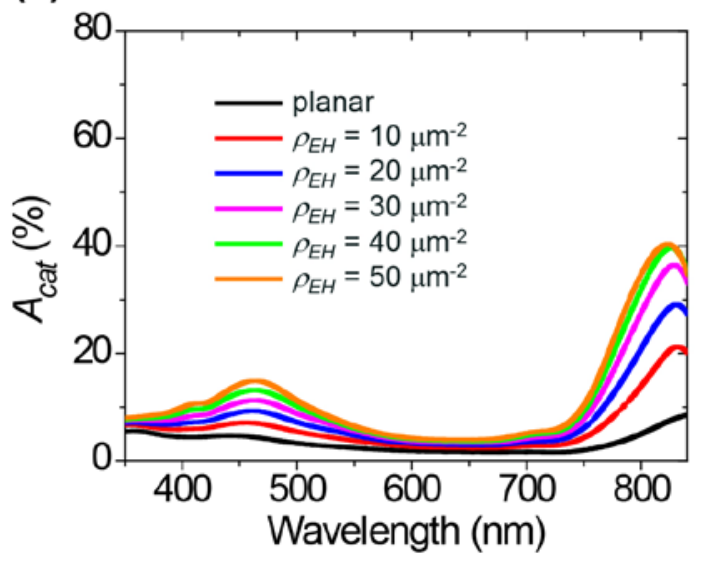

(f)

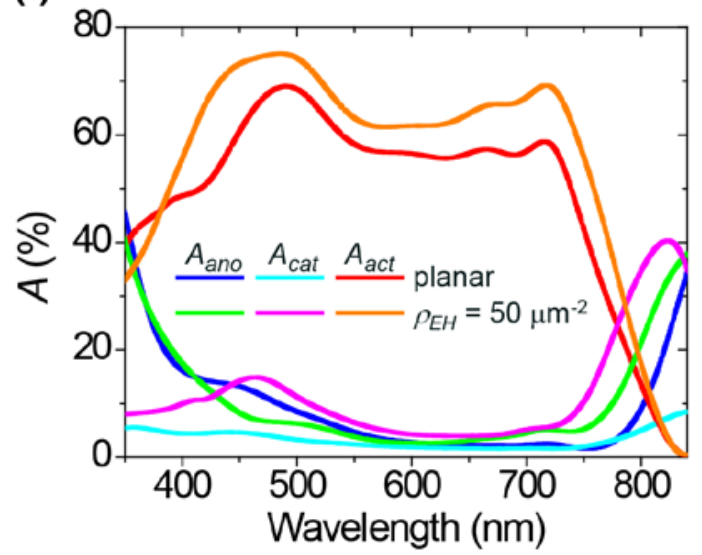

Figure S12. (a-d) Calculated absorption spectra of (a) entire cell $\left(A_{c}\right)$, (b) active layer $\left(A_{a c t}\right)$, (c) anode $\left(A_{a n o}\right)$, and $(\mathrm{d})$ cathode $\left(A_{c a t}\right)$ for the planar cell and the plasmonic cells with various $\rho_{E H S}$ of $10 \sim 50 \mu \mathrm{m}^{-2}$ at a fixed $D_{E H}$ of $140 \mathrm{~nm}$. (e) Calculated reflection $(R)$, transmission $(T)$, and entire absorption $\left(A_{c}\right)$ spectra of the planar cell and the optimal $\left(\rho_{E H}=50 \mu \mathrm{m}^{-2}\right)$ plasmonic cell at $D_{E H}=$ $140 \mathrm{~nm}$. (f) $A_{a n o}, A_{c a t}$, and $A_{a c t}$ spectra of the planar and plasmonic cells of (e). 
(a)

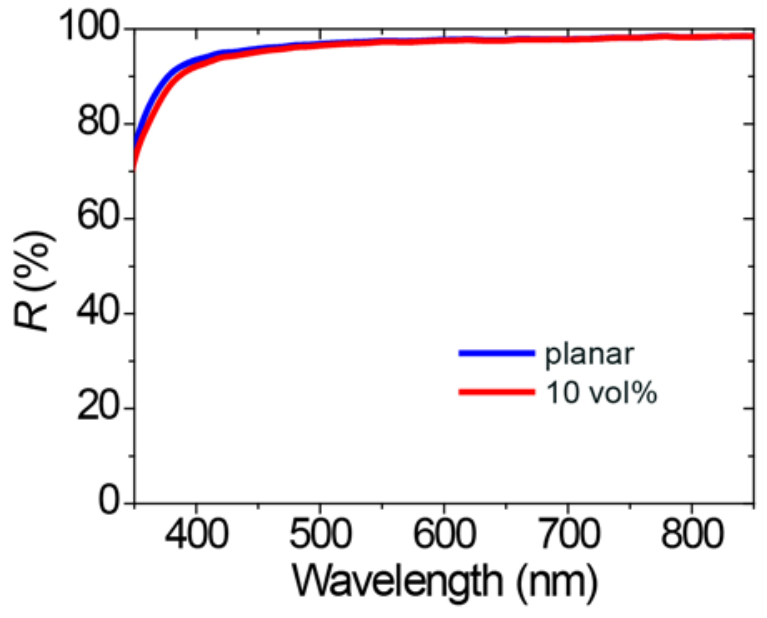

(b)

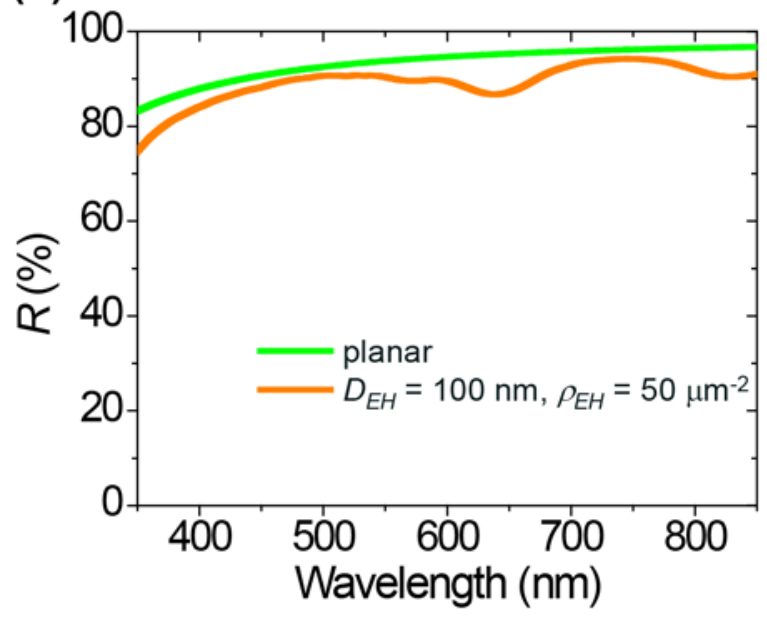

Figure S13. (a) Measured reflection spectra of planar Ag cathode and nanostructured Ag cathode formed with the $10 \mathrm{vol} \%$ blended nanoparticle solution under the air sourroundings. (b) Calculated reflection spectra of planar Ag cathode and nanostructured Ag cathode with a $D_{E H}$ of $100 \mathrm{~nm}$ and a $\rho_{E H}$ of $50 \mu \mathrm{m}^{-2}$ under the air surroundings. The modeled nanostructure in calculation has a similar $f_{\text {area }}$ value (34.4\%) to the experiment nanostructure (33.2\%). 


\section{Supporting Table}

Table S1. Measured diameters of elliptical hemispheres $\left(D_{E H} \mathrm{~S}\right)$ on the Ag cathode and operation stability of PSCs, in accordance with diameters of $\mathrm{SiO}_{2}$ seed nanoparticles $\left(D_{N P} \mathrm{~S}\right)$.

\begin{tabular}{lll}
\hline $\boldsymbol{D}_{N \boldsymbol{P}} \mathbf{( n m )}$ & $\boldsymbol{D}_{\boldsymbol{E} \boldsymbol{H}} \mathbf{( n m )}$ & Stability of device operation \\
\hline 50 & $80 \pm 20$ & stable $^{*}$ \\
\hline 70 & $100 \pm 20$ & stable \\
\hline 90 & $120 \pm 20$ & unstable \\
\hline
\end{tabular}

* 'stable' means there is no distinct leakage current. 